\title{
Ontogenic Development Of Gills In Pre To Post-Flexion Stages Larvae Of Himalayan Snow Trout Schizothorax Plagiostomus (Heckel)
}

\author{
Rajesh Rayal ${ }^{*}$ \\ ${ }^{1}$ Department of Zoology, School of Basic and Applied Sciences, Shri Guru Ram Rai University, Dehradun, \\ Uttarakhand, India \\ *Corresponding Author Email id: drrajeshrayal@gmail.com \\ Received: 04.05.2021; Revised: 24.05.2021; Accepted: 29.05.2021 \\ (C) Society for Himalayan Action Research and Development
}

\begin{abstract}
The ontogenic development of gills, including gill arch, gill filaments, and gill rakers in pre to postflexion stages larvae of Himalayan Snow Trout Schizothorax plagiostomus were studied with the objectives that this study could serve as a base for further studies about the early embryonic development and organogenesis in various fish species inhabiting hill stream environments. To obtain the pre to post-flexion stages larvae, an artificial breeding experiment was conducted during September- October on the bank of snow-fed river Alaknanda by stripping method. Further, the development of the gill apparatus was studied histologically, using light microscopy. Hatchling takes place 124-130 hours after fertilization at the incubation temperature of $19-20^{\circ} \mathrm{C}$. On second dph (day post-hatching), gill arches, gill filaments, and branchiostegal membrane began to differentiate. By the third dph, blood channels were observed in gill filaments as well as in pseudobranch. Formation of secondary lamellae, branchial arteries, elongation of the gill cover, cartilaginous rod formation in the gill arch, and the branchiostegal membrane was discernible by fourth-fifth dph. Pillar cells and afferent and efferent arteries with RBCs in primary and secondary lamellae were observed on the seventh dph. Around the onset of exclusive exogenous feeding (twelfth dph), gill rakers and a group of pillar cells with blood channels were recognizable. Well-organized and functional gill structures with increased number and size of secondary gill lamellae were present among the fifteenth-seventeenth dph larvae. The general pattern of structural and functional development of both the natural site and laboratory-reared larvae was similar, except a large amount of mucous and clustered epithelial cells among the laboratory-reared larvae, which may be due to the physiological as well as environmental stress posed by the adverse physicochemical conditions.
\end{abstract}

Keywords: Gill, Gill Filaments/Lamellae • Gill Raker $・$ Embryonic Development $・$ Ontogeny $・$ Schizothorax Plagiostomus $\bullet$ Flexion Stage.

\section{Introduction}

It is well-established fact that the gills of teleost fishes have evolved into an anatomical complex, multifunctional tissue with distinct external epithelial and internal circulatory and neural elements. It plays a very significant role in the gaseous exchange, excretion of nitrogenous waste, acid-base balance, and osmoregulation (Evans et.al. 2005). Gills are typically composed of several paired gill arches, containing arteries and veins that supply blood flow to the attached gill filaments/lamellae. The total number of lamellae constitutes the total surface area of the gills available for gas transfer. The number of gill lamellae of the fish is correlated with their size and activity; the larger and more active fish possess more gill lamellae (Evans, 1998). 
Freshwater ecosystems are typically unstable and characterized by marked natural fluctuations of temperature, $\mathrm{pH}$, dissolved oxygen, carbon dioxide, and dissolved ions, etc. The ability of fish to inhabit such a diverse environment arises from a variety of adaptive physiological mechanisms (Perry and Laurent, 1993). Himalayan snow trout Schizothorax is considered to have a great aquaculture potential and may be cultured at a commercial level especially in the cold-water bodies including the manmade reservoirs being developed for hydroelectric power projects in the Himalayan regions. However, cultured fish often have high mortality due to the ontogenetic defects and malfunctioning of various organs during early life stages (Bahuguna and Rayal, 2006a.b.c; Rayal, 2020). Due to the overexploitation (especially during breeding season), reduced and irregular water flows in hill streams (impact of hydroelectric projects in the Himalayan region), habitat erosion and shrinking fish breeding grounds, etc., the population of Schizothorax species in the Himalayan region is being declined day by day (Rayal and Bahuguna, 2006a; Rayal et.al., 2011). Keeping in view all these facts, during the present study, an attempt has been made to describe the early ontogenic development of gills or branchial respiratory system in the Himalayan snow trout Schizothorax plagiostomus from pre to post-flexion stages. This study could serve as a basis for further studies concerning the early embryonic development and organogenesis in various hill stream fishes.

\section{Material and Methods}

For obtaining the pre to post-flexion stages larvae, an artificial breeding experiment was conducted on the bank of river Alaknanda during breeding season September-October. Live brooders of Himalayan snow trout Schizothorax plagiostomus (Heckel) were collected by using Cast Net. Eggs and milt were taken by stripping the mature brooders and mixed with the help of bird feathers for 5-10 minutes. After removing the excess of milt, fertilized eggs were placed in hatching trays, glass jar hatchery, and hatching tub in the laboratory with proper aeration, temperature (17$20^{\circ} \mathrm{C}$ ), and regular water supply. Some of the fertilized eggs were also placed in hatching trays on a small stream of river to ensure proper and natural development. The behavior and developmental changes among the larvae at both the laboratory and natural sites were monitored up to the post-flexion stage. For the subsequent morpho-histological study, from hatching to postflexion stages at 4-8 hrs intervals, 5-10 larvae were fixed in different fixatives, viz. aqueous bouins, alcoholic bouins, 4\% formalin, calcium formol, and $70 \%$ alcohol, etc. For light microscopy, after completion of fixation (18-24 hrs) in bouins, samples were washed and then dehydrated in an ascending series of ethanol for embedding. Following the embedding in paraffin wax (E. Merck, $54-56^{\circ} \mathrm{C}$ melting point paraffin wax), transverse and longitudinal sections of 5$6 \mu \mathrm{m}$ were obtained by Erma rotary microtome. Serially arranged sections of paraffin-embedded material were stained with hematoxylin (nuclear stain), Iron hematoxylin, Eosin (cytoplasmic stain), and Mallory triple stain. The stained sections were mounted in DPX and then photomicrographs were taken with the help of Olympus- photo-microscopic system.

\section{Results}

At the time of hatchling (124-130 hours after fertilization at the incubation temperature of 19$20^{\circ} \mathrm{C}$ ) when larvae measured about $9 \mathrm{~mm}$ and 0.10 $\mathrm{mg}$ in length and weight respectively, jaws, gills, and opercular anlage were not discernible. On second dph (day post-hatching), gill arches and filaments began to differentiate. At this stage when larvae measured $9.5 \mathrm{~mm}$ in length and $0.11 \mathrm{mg}$ in weight, the branchiostegal membrane 
starts to cover the first-gill arch (Fig.-1). Formation of the pseudobranch also began in the anterior wall of the branchial cavity or at the base of the branchiostegal membrane. On third dph gill arches and filaments were easily distinguishable around the pharynx, some blood channels also recognizable in it, pseudobranch having blood channels was more elongated and having close resemblance with the gill filaments (Fig.-2). The formation of secondary lamellae with marginal channels was apparent in the sections of the fourth-fifth dph larvae. At this stage, branchial arteries were discernible in each gill arch. Elongation of the gill cover, formation of cartilaginous rods in the gill arch, and branchiostegal membrane was also observed (Fig.-3). On the seventh dph, elongated gill filaments (Primary and secondary lamellae) with some pillar cells and branchial arteries (afferent and efferent) with RBCs were visible (Fig.-4). During eighth-ninth dph, secondary lamellae and branchial arteries were more differentiated (Fig.5). The branchiostegal membrane becomes perfectly cartilaginous. Pseudobranch was more developed and some secondary lamellae-like structures were present in it. On twelfth dph (around the onset of exclusive exogenous feeding); pillar cells (mesenchymal cells) lining the blood channels of secondary gill lamellae and rudiments of gill rakers were recognizable (Fig.6). Fifteenth-seventeenth dph larvae were observed with well-organized and functional gill structures. Secondary gill lamellae were increased in number as well as in size (Fig.-7-8). Branchiostegal rays lay down in the branchiostegal membrane. Goblet cells were also observed during this period (Fig.-9). The general pattern of structural and functional development ion regulatory activities. of both the natural site and laboratory-reared larvae was similar except for a large number of mucous cells with a huge amount of mucous especially among those laboratory-reared larvae, which were observed sluggish and later on got mortality. Some clustered epithelial cells were also noticed among such types of larvae (Fig.-10).

\section{Discussion}

During the ontogenic developmental study of gills in pre to post-flexion stages larvae of Himalayan Snow Trout S. plagiostomus, some variations were observed in the timing and onset of morphofunctional developmental features as described by few ichthyologists in other fish species. In Oreochromis niloticus the basic structures of the branchial respiratory system were established on second-third dph; when incubation temperature was $27-29{ }^{\circ} \mathrm{C}$ and hatching takes place after 100hrs of fertilization (Morrison et.al, 2001). While in Anabas testudineus, the gill structures began to differentiate by $14 \mathrm{hrs}$ after hatching and become functional up to third dph (Hughes et.al, 1986). In the case of the present study on $S$. plagiostomus larvae, this process takes a long time, where hatching took place after $124-130 \mathrm{hrs}$ of fertilization at $19-20^{\circ} \mathrm{C}$ incubation temperature. Differentiation of gill structures begins by the second dph and it becomes well functional up to the tenth-twelfth dph (240-288hrs after hatching). This low temperature and the long incubation period were found directly correlated to the morpho-functional development of gills in $S$. plagiostomus larvae. During late pre-flexion as well as in the early flexion stage when irregular or partial branchial respiration set in, the larval red layer performs the gas exchange and 


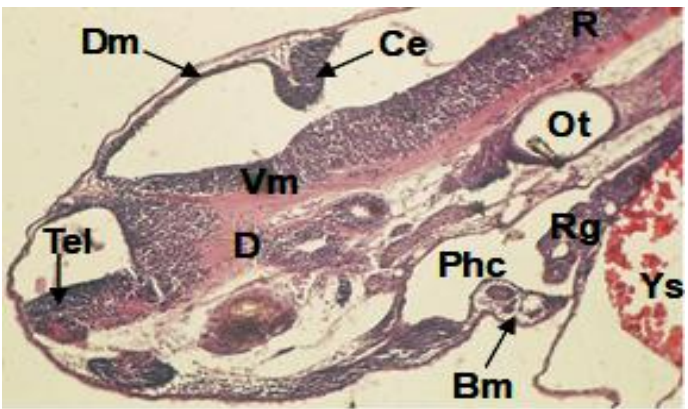

Fig 1: L.S. of second dph larvae showing Brain, rudimentary gill and branchiostegal membrane, etc. (H.E. 70X).

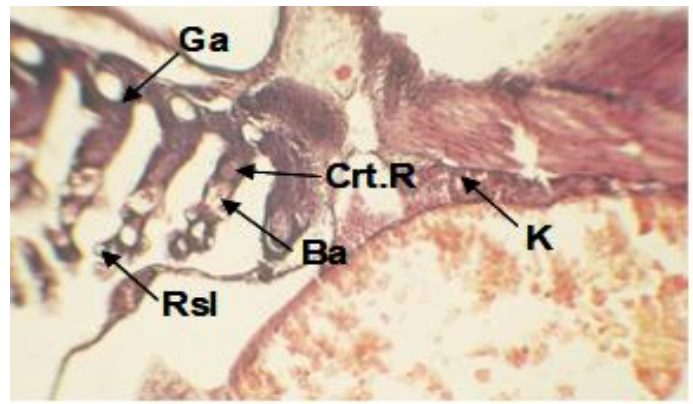

Fig 3: L.S. of fifth dph larvae showing gill filaments, rudiments of secondary gill lamellae, branchial blood vessels (H.E. 100X).

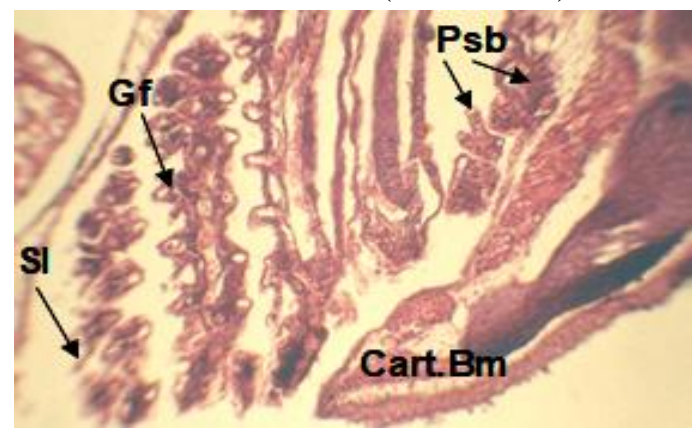

Fig 5: L.S. of eighth dph larvae through branchial region showing $\mathrm{RBCs}$ in the efferent and afferent artery, more developed gill filaments with secondary gill lamellae, etc. (H.E. 280X).

Shifting of the gas exchanging process from red layer to gills begins by flexion stage (sixthseventh dph) or before the initiation of exclusive exogenous feeding. The corresponding indicator for shifting of the gas exchange process was the appearance of secondary gill lamellae and RBCs in the blood channels. Similar phenomena were

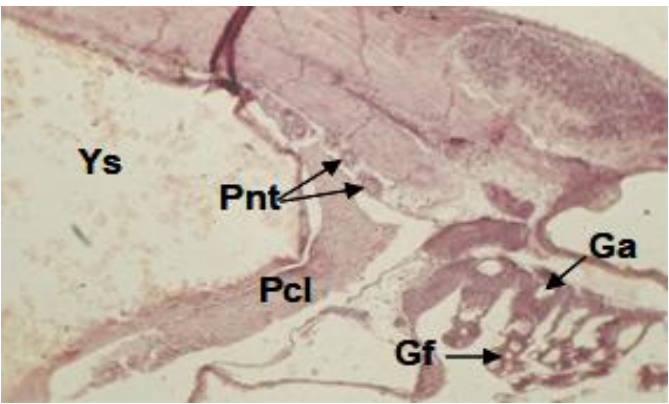

Fig 2: L.S. of third dph larvae showing gill arches, filaments, etc. (H.E. 70X).

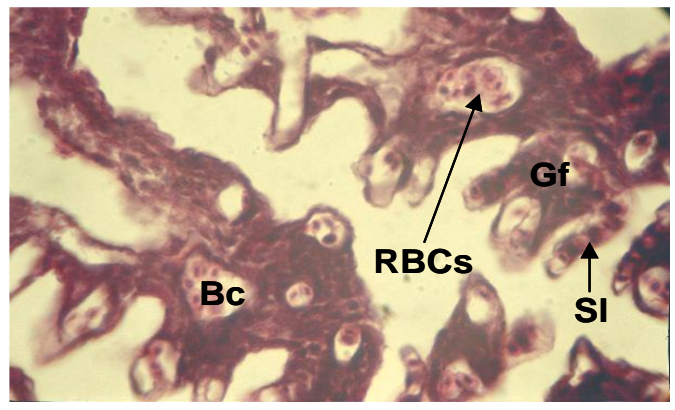

Fig 4: L.S. of seventh dph larvae showing gill filaments, some secondary gill lamellae with pillar cells and RBCs in blood vessels, etc. (H.E. 400X).

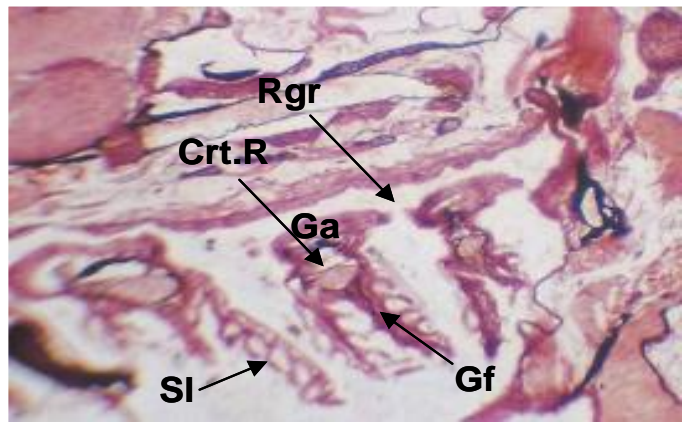

Fig 6: L.S. of twelfth dph larvae showing gill arches with cartilaginous rods, well-differentiated primary and secondary filaments, efferent and afferent arteries, rudiments of gill raker, etc. (H.E. 100X).

also reported by Nabil et.al. (1987) and Rombough (2004) in some other teleosts larvae. Simultaneously with the growth of larvae, the number and size of gill filaments and secondary lamellae (which are the actual site for gas exchange) with groups of pillar cells surrounding the blood channels also increased 
in the fifteenth dph to supply the gradually increasing oxygen demand in the $S$.

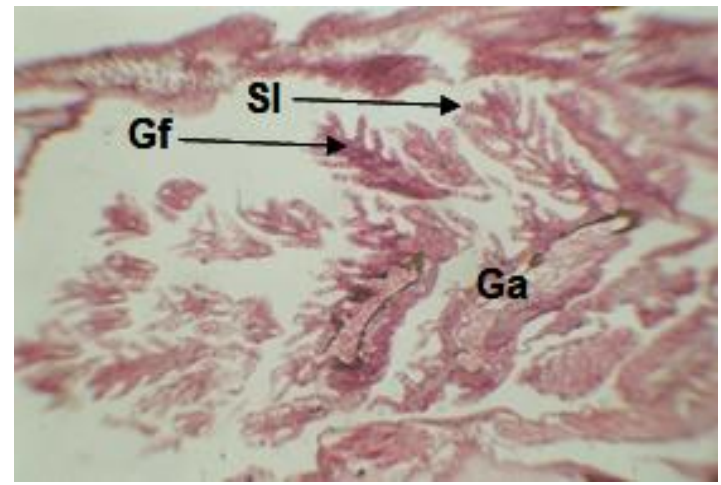

Fig 7: L.S. of fifteenth dph larvae through branchial region showing gill filament, welldeveloped secondary lamellae, etc. (H.E. 100X).

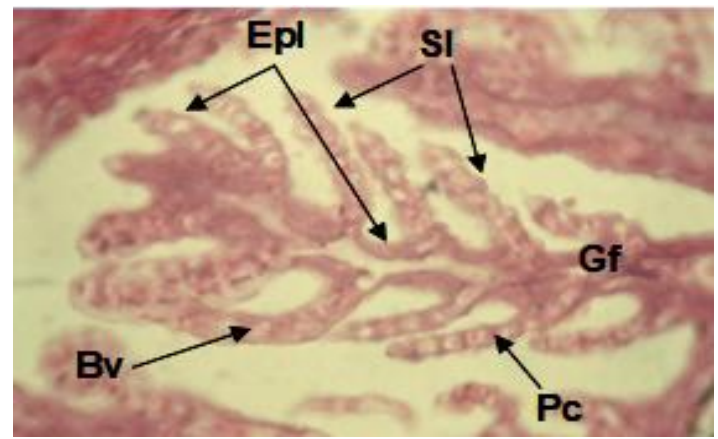

Fig 9: T.S. of seventh dph larvae through gill region showing elongated gill filaments with many mucous cells and increasing number as well as the size of secondary lamellae. (H.E. 100X).

\section{Abbreviations of figures:}

$\mathrm{Ba}=$ branchial artery

$\mathrm{Bm}=$ branchiostegal membrane

Cart.Bm = cartilaginous branchiostegal membrane

Cep $=\quad$ clustered epithelial cells

Crt.R = cartilaginous rod

$\mathrm{Dm}=$ dorsal mid brain

$\mathrm{Ga}=$ gill arch

$\mathrm{K}=$ kidney

$\mathrm{Mc} \quad$ mucous cell

The presence of pseudobranch with secondary lamellae-like structure and RBCs within blood plagiostomus larvae.

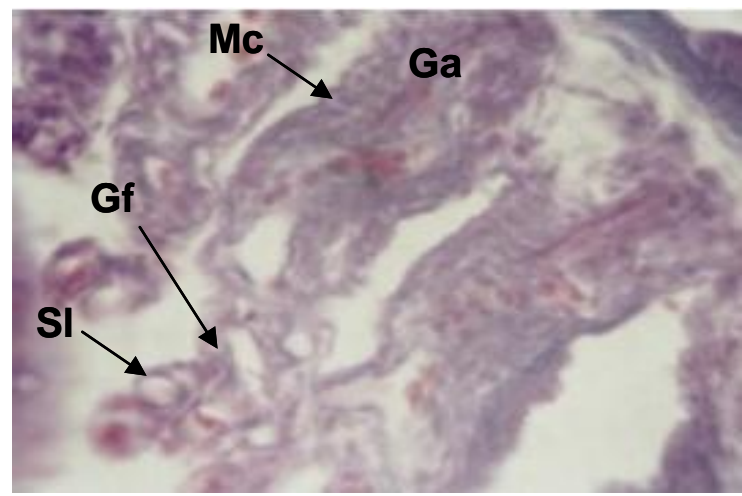

Fig 8: L.S. OF fifteenth dph larvae through branchial region showing well-organized gill structures.

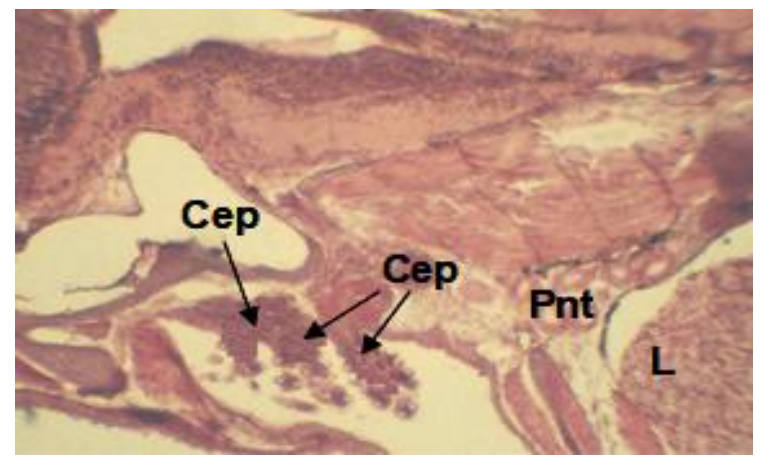

Fig 10: L.S. of tenth dph laboratory larvae showing the formation of a cluster of epithelial cells in the gills (H.E. 100x) channels are evidence of its accessory respiratory function during pre to post-flexion stages. In this 
respect, our findings are supported by the opinion of Evans (1998) and Morrison et.al. (2001). In fifteenth $\mathrm{dph} S$. plagiostomus larvae; a large number of pillar cells around the blood channels of secondary gill lamellae were visible. These cells form the small tunnels within each secondary lamella that acts as a channel for the blood to perfuse through it. Pillar cells also regulate gas exchange across the surfaces of secondary gill lamellae, and due to their expansion and contraction ability, they may increase or decrease the size of blood flowing tunnels allowing more or less blood to perfuse through it. A similar mechanism of increasing and decreasing the size of blood channels of secondary gill lamellae has been suggested by Laurent and Dunel (1976) and Evans (1998).

Depending upon the content of dissolved oxygen (Low or High) in water, pillar cells contract or expand to allow less or more amount of blood to rush through the lamellae to pick up the oxygen. Water flows through the lamellae in one direction while blood in the channels flows in the opposite direction through the epithelial layer. This creates a countercurrent flow, maximizing the rate of oxygen transfer (Newstead, 1967; Garhm, 1997; Evans, 1998). This view also supports the observations of the present study in hill stream Himalayan snow trout Schizothorax plagiostomus larvae inhabiting high dissolved oxygen and low water temperature environment with expanding pillar cells and allowing more blood to rush through the lamellae. As the chances of ion loss may also increase with the increase in the surface area of the gills, the number and size of goblet cells, which controls the ion loss or water-influx also began to increase in fifteenth-seventeenth dph larvae of Schizothorax plagiostomus.

Gill rakers act as a sieve in the filtration of micro food items from the water and thus, a precise relationship may exist between the number, length, and space of gill rakers, and proportion as well as the size of various food items in the diet of post-flexion larvae of Schizothorax plagiostomus. The presence of closely spaced gill rakers indicates the beginning of planktonic filter feeding at this stage. Young (1962), Kapoor (1965), Walter (1966), Bahuguna and Singh (1984) assumed a similar correlation between the quality as well as quantity of food items in the diet and gill morphology. The presence of clustered epithelial cells and a large number of mucous cells with the huge amount of mucous among the laboratory-reared larvae of Schizothorax plagiostomus may be due to the physiological as well as environmental stress posed by the adverse physicochemical conditions (Rayal and Bahuguna, 2006b; Rayal, 2020). Mucous from the mucous secreting cells in the gills of Schizothorax plagiostomus larvae may probably perform a variety of functions like prevention of mechanical abrasion, minimizing the various kinds of pathogenic infections, precipitation of some heavy metals as well as prevention of loss of ions (Fletcher, 1978; Rayal and Bahuguna, 2006c; Mir and Channa, 2011).

\section{Acknowledgment}

The author sincerely acknowledges Prof. S.N. Bahuguna, Department of Zoology and Biotechnology, Srinagar Campus, H.N.B. Garhwal University (Central University) Srinagar Garhwal, for constant supervision and encouragement.

\section{References}

Bahuguna SN and Rayal R (2006.a). Histomorphological study of the optic tissue in the larvae of Himalayan Snow Trout Schizothorax plagiostomus (Heckel) Aquacult. Vol. 7(2): 153-158

Bahuguna SN and Rayal R (2006.b). Morphohistological study of the brain in Schizothorax plagiostomus (Heckel) larvae 
with special reference to its feeding habit Him. J. Envt. Zool. Vol. 20(2): 231-235

Bahuguna SN and Rayal R (2006.c). Posthatching developmental study of the hepatic and pancreatic structures in the laboratoryreared larvae of Himalayan snow trout Schizothorax plagiostomus (Heckel) Flora and Fauna12 (1): 45-50

Bahuguna SN and Singh HR (1984). Food and feeding habits with gross morphology of the alimentary tract of a hill stream fish Barilius vagra (Ham) J. Anim. Morph. Physiol. 31 (1 and 2):183-187

Evans DH, Piermarini PM and Choe KP (2005). The Multifunctional Fish Gill: Dominant Site of Gas Exchange Osmoregulation Acid-Base Regulation and Excretion of Nitrogenous Waste Physiological Reviews 85 (1): 97-177

Evans DH (1998). The physiology of fishes. Second edition CRC Marine Science Series 9 CRC Press: Boca Raton. pp 519

Fletcher TC (1978). Defense mechanism in fish. $J$. Histochem. Cytochem. 32: 681-689

Graham JB (1997). Air-Breathing Fishes. San Diego CA: Academic 1-299

Hughes GM, Munshi D, JS and Ojha J (1986). Post-embryonic development of water and air-breathing organs of Anabas testudineus (Bloch) J. of Fish Biol. 29: 443-450

Kapoor BG (1965). Gill-rakers of a few Indian freshwater fishes Ann. Mus. Sto. Nat. Genova75: 126-143

Laurent P and Dunel S (1976). Functional organization of the teleost gill In Blood Pathway Acta. Zool. (Stockholm). 57: 189209

Mir IH and Channa A (2011). Mucous Cells in the Gills of Snow Trout, Schizothorax curvifrons Heckel (Pisces, Cypriniformes, Cyprinidae). Cytologia 76, 213-218.

Morrison CM, Tsutomu $\mathrm{M}$ and James RWJr (2001). Histological Study of the Development of the Embryo and Early Larva of Oreochromis niloticus (Pisces: Cichlidae) J of Morpho. 247:172-195

Nabil, El-Fiky; Silvia Hinterleitner and Wolfgang W. (1987). Differentiation of swimming muscles and gills, and development of anaerobic power in the larvae of cyprinid fish (Pisces: Teleostei). Zoomorphology (Historical Archive). 107(2): 126-132.

Newstead and JD (1967). Fine structure of the respiratory lamellae of teleostean gills $Z$. Zellfrosch. Mikrosk. Anat. 79: 396-428

Perry Steve F and Pierre Laurent (1993). Environmental Effects on Fish Gill Structure and Function in Fish Ecophysiology, Chapman \& Hall Fish and Fisheries Series, edited by JC Rankin and FB Jensen Dordrecht: Springer Netherlands. Pp 231-64

$* * * * * *$ 